\title{
Neuron Dysfunction Is Induced by Prion Protein with an Insertional Mutation via a Fyn Kinase and Reversed by Sirtuin Activation in Caenorhabditis elegans
}

\author{
Nicolas Bizat, ${ }^{1,2,3}$ Jean-Michel Peyrin, ${ }^{4}$ Stephane Haïk, ${ }^{5,6,7}$ Véronique Cochois, ${ }^{3}$ Patrick Beaudry, ${ }^{3}$ \\ Jean-Louis Laplanche, ${ }^{3}$ and Christian Néri ${ }^{1,2}$ \\ ${ }^{1}$ Institut National de la Santé et de la Recherche Médicale (Inserm), Unit 894, Laboratory of Neuronal Cell Biology and Pathology, ${ }^{2}$ Université Paris \\ Descartes, Equipe d'accueil 4059, 75014 Paris, France, ${ }^{3}$ Université Paris Descartes, Laboratory of Prion Biology Diseases and Cellular Regulation, Equipe \\ d'accueil 3621, 75006 Paris, France, ${ }^{4}$ Institut National de la Recherche Agronomique, Unit for Molecular Immunology and Virology, 78352 Jouy-en-Josas, \\ France, ${ }^{5}$ Inserm, Unité Mixte de Recherche en Santé (UMRS) 975, 6Université Pierre et Marie Curie, Université Paris 6, UMRS 975, Centre de Recherche de \\ l'Institut du Cerveau et de la Moelle Epinière, Pitié-Salpêtrière, and ${ }^{7}$ Centre National de la Recherche Scientifique, Unité Mixte de Recherche 7225,75013 \\ Paris, France
}

\begin{abstract}
Although prion propagation is well understood, the signaling pathways activated by neurotoxic forms of prion protein (PrP) and those able to mitigate pathological phenotypes remain largely unknown. Here, we identify $s r c-2$, a Fyn-related kinase, as a gene required for human PrP with an insertional mutation to be neurotoxic in Caenorhabditis elegans, and the longevity modulator sir-2.1/SIRT1, a sirtuin deacetylase, as a modifier of prion neurotoxicity. The expression of octarepeat-expanded PrP in C. elegans mechanosensory neurons led to a progressive loss of response to touch without causing cell death, whereas wild-type PrP expression did not alter behavior. Transgenic PrP molecules showed expression at the plasma membrane, with protein clusters, partial resistance to proteinase $\mathrm{K}$ (PK), and protein insolubility detected for mutant PrP. Loss of function (LOF) of $s r c-2$ greatly reduced mutant PrP neurotoxicity without reducing PKresistant PrP levels. Increased sir-2.1 dosage reversed mutant PrP neurotoxicity, whereas sir-2.1 LOF showed aggravation, and these effects did not alter PK-resistant PrP. Resveratrol, a polyphenol known to act through sirtuins for neuroprotection, reversed mutant PrP neurotoxicity in a sir-2.1-dependent manner. Additionally, resveratrol reversed cell death caused by mutant PrP in cerebellar granule neurons from prnp-null mice. These results suggest that Fyn mediates mutant PrP neurotoxicity in addition to its role in cellular PrP signaling and reveal that sirtuin activation mitigates these neurotoxic effects. Sirtuin activators may thus have therapeutic potential to protect from prion neurotoxicity and its effects on intracellular signaling.
\end{abstract}

\section{Introduction}

Misfolded prion proteins are involved in several neurodegenerative disorders including Creutzfeldt-Jakob disease (CJD) in humans, bovine spongiform encephalopathy (BSE) in cattle, and scrapie in goat and sheep. Human prion disease may be sporadic, acquired through exposure to prion-infected tissues, or inherited through mutations of the prion protein gene PRNP (Prusiner and Hsiao, 1994). There is a wide variety of phenotypic variation in CJD that is not encountered in other neurodegenerative disor-

Received Nov. 24, 2009; revised Jan. 22, 2010; accepted Feb. 18, 2010.

This work was supported by Institut National de la Santé et de la Recherche Médicale, Institut National de la Recherche Agronomique, Université Paris Descartes, and the Groupement d'Intérêt Scientifique (GIS) "Infections à prions," Paris, France. N.B. was a recipient of a postdoctoral fellowship from GIS "Infections à prions." We thank Heidi A. Tissenbaum for the C. elegans geln 3 strain, Sylvain Lehmann for the mouse PrP plasmids, A. Fire for the C. elegans expression vectors, and J. Alex Parker for constructive discussions.

Correspondence should be addressed to Christian Néri, Institut National de la Santé et de la Recherche Médicale, Laboratory of Neuronal Cell Biology and Pathology, Center for Psychiatry and Neuroscience U894, 2-ter rue d'Alésia, 75014 Paris, France. E-mail: christian.neri@inserm.fr.

J.-M. Peyrin's present address: Centre National de la Recherche Scientifique, Neurobiology of Adaptative Processes, UMR 7102, 75005 Paris, France.

DOI:10.1523/JNEUROSCI.5831-09.2010

Copyright $\odot 2010$ the authors $\quad 0270-6474 / 10 / 305394-10 \$ 15.00 / 0$ ders (Aguzzi et al., 2008a). Additionally, the genetic modifiers of prion diseases remain unknown, notably those that may be associated with inherited CJD. The genetic modification of prion disease may involve the genes that modulate pathogenic PrP toxicity. Interestingly, the activity of cellular prion protein $\left(\operatorname{PrP}^{\mathrm{C}}\right)$, a glycoprotein anchored at the membrane, involves numerous ligands and signaling pathways (Westergard et al., 2007; Aguzzi et al., 2008b; Linden et al., 2008). Signaling by $\operatorname{PrP}^{\mathrm{C}}$ may notably involve caveolin-1, FYN kinases, and ERK1/2 kinases (MouilletRichard et al., 2007) as well as the cAMP/protein kinase A, MAP kinase, and PI3-kinase/Akt pathways (Linden et al., 2008), suggesting that the modulators of prion neurotoxicity may belong to the "core signaling machinery" essential for neuron activity and, more largely, for cell survival.

The conversion of $\mathrm{PrP}^{\mathrm{C}}$ or mutant $\mathrm{PrP}$ into the misfolded isoform $\left(\mathrm{PrP}^{\mathrm{Sc}}\right)$ confers partial resistance to proteolytic digestion and detergent insolubility (McKinley et al., 1983; Bolton et al., 1984) and may be central to prion disease pathogenesis (Aguzzi et al., 2008b). However, PrP molecules carrying pathogenic mutations can be neurotoxic in the absence of $\operatorname{PrP}^{\mathrm{C}}$ (Lehmann and Harris, 1996; Telling et al., 1996; Chiesa et al., 1998), and their 
study may provide insight into the cellular pathways for prion neurotoxicity (Solomon et al., 2009). Among these mutations, insertional mutations consisting of 1-9 additional copies of an octarepeat are associated with dominantly inherited forms of CJD (Prusiner and Hsiao, 1994). These mutations may direct the folding of the protein toward the $\mathrm{PrP}^{\mathrm{Sc}}$ conformation, and could initiate a self-conversion process (Leliveld et al., 2006). We previously identified a peculiar French family with early age at onset, prominence of psychiatric symptoms, lengthy clinical course, and a neuropathological phenotype of Gerstmann-SträusslerScheinker syndrome associated with eight extra octarepeats in PrP (PG13-PrP) (Laplanche et al., 1999). Here, we expressed PG13-PrP in nematode touch receptor neurons to establish a model of prion neurotoxicity. These neurons control the response to gentle touch, a well defined phenotype suitable in quantitative studies of neurotoxicity. While Caenorhabditis elegans contains proteins with putative prion-like properties (Iwasaki et al., 1992), C. elegans does not have a PrP homolog and is thus suitable to manipulate the $\operatorname{PrP}^{\mathrm{C}}$-independent effects of prion neurotoxicity. Additionally, C. elegans was instructive to uncover the neuroprotective role of longevity modulators such as the sirtuin sir-2.1/SIRT1 in animals expressing a N-terminal portion of the Huntington's disease (HD) protein (Parker et al., 2005), a protein not conserved in nematodes. Here, the biochemical characterization and the manipulation of mutant $\operatorname{PrP}$ in $C$. elegans together indicated that sirtuin activation protects from a component of mutant PrP neurotoxicity that involves a Fynrelated kinase activity. Our data also indicate that sirtuin activators have therapeutic potential to protect from the effects of prion neurotoxicity on intracellular signaling.

\section{Materials and Methods}

\section{C. elegans}

Reporter constructs. The various constructs, human wild-type $\operatorname{PrP}, \mathrm{mu}-$ tated PrP with 8 additional octarepeat (PHGGGWGQ) expansion, and GFP, were cloned into the EcoRV-EcoRI site of the $P_{\text {mec- }}$ plasmid, pPD118.44 (gifts from Andy Fire, Washington University, St. Louis, $\mathrm{MO}$ ), to create $P_{\text {mec- } 7} \mathrm{GFP}$ and $P_{\text {mec }-7} \mathrm{PrP}$ constructs. The normal Wt-PrP and the mutated PG13-PrP constructs were derived from human DNA (Laplanche et al., 1999). Primers used to amplification of human PrP were as follows: PrP-f, 5'-CCGGATATCCGGATGGCGAACCTTGGCTGCTGGA-3'; PrP-r, 5'-CGGGAATTCCGGTCATCATCATCCCACTATCAGGAAGATG-3'. All constructs were sequenced to verify integrity.

Genetic manipulations. Nematodes were maintained following standard methods (Brenner, 1974). Some nematode strains used in this work were provided by the Caenorhabditis elegans Genetics Center CGC, which is funded by the National Institutes of Health National Center for Research Resources. Transgenic animals were generated by standard transformation techniques (Mello and Fire, 1995). The various PrPencoding plasmids were coinjected with a wild-type $l i n-15$ and $P_{\text {Str-1 }}$ GFP marker plasmid into the gonads of young adult lin-15(n765) hermaphrodites. The concentrations used were $20 \mathrm{ng} / \mu \mathrm{l}$ for PrP-encoding plasmids, $20 \mathrm{ng} / \mu \mathrm{l}$ for GFP marker-encoding plasmids $\left(P_{S t r-1} \mathrm{GFP}\right.$ and $\left.P_{\text {mec- } 7} \mathrm{GFP}\right)$, and $50 \mathrm{ng} / \mu \mathrm{l}$ for the wild-type lin-15 marker. Extrachromosomal arrays showing a similar level of transgene expression as shown by RT-PCR and Western blotting were retained for further studies. Mutant strains were first crossed with $\operatorname{lin}-15(n 765)$ males. These strains were then crossed with our PrP strains (two strains/PrP allele), rescuing the lin-15(n765) phenotype. The mutants used in this study included sir-2.1(ok434), geIn3(sir-2.1(O/E)) (Tissenbaum and Guarente, 2001), and src-2(ok819) (Hirose et al., 2003).

Mechanosensory assays. Touch response assays and visualization of $C$. elegans transgenics were performed as described previously (Parker et al., 2001). Touch tests involved scoring for the response to light touch at the tail by using a fine hair. Touch test were performed by scoring 10 touches at the tail of the animal for a minimum of 200 animals per genotype and with three independent assays performed. Ordinarily, wild-type animals will respond by backing away from touch. The responses were recorded for every animal such that, for example, 3 responses out of 10 at the tail is given as $30 \%$ responsiveness, and the mean values for responsiveness were retained for comparison of nematode groups. Wt-PrP animals and PG13-PrP animals were used as internal controls for all of the independent assays performed, and percentage rescue was calculated as (test $\%$ - control $\%) /(\mathrm{Wt}-$ PrP\% - PG13-PrP\%), where "test" and "control" refer to the genetic background tested. With this formula, a negative value means aggravation, and the greatest amount of rescue as expected by comparing the baseline for Wt-PrP and that for PG13-PrP (maximal achievable rescue) is 100\%.

Biochemical analysis and Western blotting. For protein extraction, nematodes were collected and incubated in M9 buffer with $4 \%$ glucose during $15 \mathrm{~min}$ and were concentered after centrifugation at $1000 \times g$ for $30 \mathrm{~s}$. They were then sonicated during $30 \mathrm{~s}$ in lysis buffer containing PBS, $0.1 \%$ Triton $\mathrm{X}-100$, and a protease inhibitor cocktail (Roche). Protein concentrations were determined using the BCA method (Pierce) according to the manufacturer's instructions. To test for PrP expression, protein samples were directly subjected to Western blotting analysis. To test for protease resistance, the homogenates were digested with proteinase $\mathrm{K}$ (PK, Roche) at final concentration ratio total protein/PK: $1 / 10,000^{\mathrm{e}}$ for $1 \mathrm{~h} 45 \mathrm{~min}$ at $37^{\circ} \mathrm{C}$. To test for PrP solubility, worm homogenates were incubated with $2 \times$ detergent buffer (PBS, $2 \% N$-laurylsarcosyl, and $2 \%$ SDS) for $30 \mathrm{~min}$ under agitation and at room temperature (v/v). One fraction of the samples was saved for Western blotting (total fraction) and the remaining was centrifuged $30 \mathrm{~min}$ at $15,000 \times g$ and at room temperature. The supernatants were removed to fresh tubes and the pellets resuspended in $1 \times$ detergent buffer (PBS, $1 \% \mathrm{~N}$-laurylsarcosyl, and $1 \%$ SDS). Protein concentrations were determined for each fraction. For Western blotting analysis, proteins ( $40 \mu \mathrm{g} /$ line $)$ were separated by SDS-PAGE $12 \%$. After blot transfer, nitrocellulose membranes were incubated overnight at $4^{\circ} \mathrm{C}$ with the PrP antibody 3F4 (Covance; 1:2000). The blots were then incubated with horseradish peroxidase-conjugated secondary antibody (Biorad; 1:5000), and peroxidase activity was detected using ECL Plus reagent (GE Healthcare). Signal quantification was performed using standard scanning and image analysis tools.

$\operatorname{PrP}$ analysis based on the scrapie-associated fibril protocol. This analysis was performed as previously described (Levavasseur et al., 2008; Brandel et al., 2009). Brain samples were homogenized at $20 \%$ (w/v) using a Ribolyser (Bio-Rad) in 5\% glucose. C. elegans proteins were prepared as indicated above. One volume of a $20 \% \mathrm{NaCl}$ solution and one volume of a detergent solution (20\% N-laurylsarcosyl, 2\% SB3-14, and Tris $20 \mathrm{~mm}$, $\mathrm{pH} 7.4$ ) were added to one volume of $20 \%$ brain homogenate. This mixture had a final $\mathrm{pH}$ of 7.6 and was digested with proteinase $\mathrm{K}$ at $10 \mu \mathrm{g} / \mathrm{ml}$ for $1 \mathrm{~h}$ at $37^{\circ} \mathrm{C}$. PrP resistant to PK was then purified according to the scrapieassociated fibril protocol including a centrifugation at 27,500 $\times g$ for $2 \mathrm{~h}$ at $20^{\circ} \mathrm{C}$ on $20 \%$ sucrose cushion. Samples were subjected to SDS-PAGE $12 \%$. Proteins were electroblotted onto nitrocellulose membrane. Immunoblotting was performed using the mouse monoclonal antibodies $3 \mathrm{~F} 4$ at $0.2 \mu \mathrm{g}$ of $\mathrm{IgG} / \mathrm{ml}$ and detected with an ECL kit (GE Healthcare).

$R N A$ isolation and RT-PCR. The expression level of PrP mRNAs was determined using quantitative RT-PCR. RNA was isolated from young adult animals upon synchronization using sonication followed by extraction with a Qiagen RNeasy kit and DNase I (Sigma) treatment (as per the manufacturer's protocol). Single-strand cDNA synthesis was performed using oligoDT priming and 200 ng of total RNA with Taqman Reverse Transcriptase Multiscribe (Applied Biosystems). Quantitative PCR was performed using SYBR Green with the ABI PRISM 7700 Sequence Detection System (Applied Biosystems) and the following oligonucleotides: 5'-3', PrP-f (TGCTGGATGCTGGTTCTCTT), PrP-r (GGCTGCCCCCAGTGTTCCA), col-1f (CCAACATCTCCAAGTTATGAAA), and col-1r (GATTGTATGTCGGCGAGGAT). Assays and data analysis were performed according to the manufacturer's protocol (User Bulletin \#2, ABI PRISM 7700 Sequence Detection System, PerkinElmer). All samples were run at least in triplicate using $\mathrm{Col}-1$ as the calibrator gene with a dilution of 1:100 of cDNA. The amount of target, normalized to an endogenous reference $(\mathrm{PrP})$ and relative to the calibrator (Col-1), was 
calculated using the $2^{-\Delta \Delta C T}$ method and statistical significance determined using paired $t$ tests (Livak and Schmittgen, 2001).

Immunohistochemistry and fluorescence microscopy. Nematodes were permeabilized and fixed as previously described (Finney and Ruvkun, 1990). The PrP antibody SAF-32 (CEA; 1:400) was incubated with the specimens overnight at $4^{\circ} \mathrm{C}$. The fluorescently conjugated $\mathrm{Cy}-3$ secondary antibody (Alexa; 1:800) was applied for $2 \mathrm{~h}$ at room temperature. Specimens were washed and stained with DAPI before mounting. Animals were examined with a Zeiss Axioscope epifluorescence microscope (Zeiss) equipped with a Coolsnap camera and MetaView software (Universal Imaging). Transgenic animals were examined for aggregation and axonal morphology of PLM cells using a $\times 100$ objective. A minimum of 100 animals/strain was scored. Examination of PLM cell morphology was performed using a $\times 63$ objective, and 100 animals/strain were scored.

Confocal microscopy. Confocal sections of $0.4 \mu \mathrm{m}$ were taken, and GFP expression and PrP immunostaining were detected by using FITC and Cy-3 filters, respectively. This was conducted on a confocal microscope (TCS, Leica) and image analysis performed using the ImageJ software. A minimum of 10 animals/strain was scored.

Drug assays in C. elegans. Quinacrine and resveratrol were obtained from Sigma. Synchronized L1 larvae were obtained by hypochlorite extraction and incubated with drugs in 96-well plates in $50 \mu \mathrm{l}$ of S-Media with bacteria (OP50), $30 \mu \mathrm{g} / \mathrm{ml}$ streptomycin, and $1 \%$ DMSO, at $20^{\circ} \mathrm{C}$ until they reached young adulthood. Animals were then transferred to agar plates, allowed to recover, and assayed for light touch response. A minimum of 200-250 worms/test were scored per dose, and at least four independent assays performed. Wt-PrP animals and PG13-PrP animals were used as internal controls for all of the independent assays performed, and percentage rescue was calculated as (test $\%$ - control\%)/ (Wt-PrP\% - PG13-PrP\%), where "test" and "control" refer to the genetic background tested. Scoring for abnormalities in PLM cells of treated animals was performed as described above.

\section{Mouse cerebellar granule neurons}

Cell culture and transfection. Primary cultures of cerebellar granule neurons (CGN) were established as previously described (Cronier et al., 2007). Briefly, CGN cells were extracted from 5- or 6-d-old PrP knockout mice Zurich I (Büeler et al., 1992) by enzymatic and mechanical dissociation. Batches (5 millions cells) of freshly dissociated cerebellar granule neurons were transfected using Amaxa technology with $10 \mu \mathrm{g}$ of endofree purified plasmids (Qiagen) encoding either Wt-PrP or PG14$\operatorname{PrP}$, and PrP constructs inserted in a pcDNA3 vector were a kind gift from Dr. S. Lehmann (CNRS, Montpellier, France) (Lehmann and Harris, 1995). Typical transfection yields were $\sim 50 \%$. Cells were then plated at a density of 1900 cells $/ \mathrm{mm}^{2}$ on plastic culture wells coated with 10 $\mu \mathrm{g} / \mathrm{ml}$ poly-D-lysine and incubated at $37^{\circ} \mathrm{C}$ with $6 \% \mathrm{CO}_{2}$. Cells were cultured for $3 \mathrm{~d}$ in an antioxidant-containing medium (DMEM-GlutaMAX I (Invitrogen) supplemented with 10\% FCS (BioWhittaker), $20 \mathrm{~mm} \mathrm{KCl}$, penicillin, and streptomycin (Invitrogen) and completed with N2 and B27 (Invitrogen). Seventy-two hours after transfection (day 3 ), the cell culture medium was changed for an antioxidant-free medium containing vehicle (DMSO) or $1 \mu \mathrm{M}$ resveratrol (DMEM-GlutaMAX I, supplemented with $10 \%$ FCS, $20 \mathrm{~mm} \mathrm{KCl}$, penicillin and streptomycin, N2, and antioxidant-free B27 supplement). Seventy-two hours after treatment (day 6), cells were fixed and processed for immunocytochemistry.

Immunofluorescence. Cells were fixed in PBS containing 4\% paraformaldehyde and $4 \%$ sucrose for $10 \mathrm{~min}$ at room temperature and permeabilized (5 min with PBS and $0.1 \%$ Triton X-100). PrP was detected using $\mathrm{mAb} 4 \mathrm{~F} 2$ and neuronal population was specifically labeled by using polyclonal Ab raised against MAP2 (Sigma). Cells were then incubated with appropriate Alexa-conjugated secondary antibodies and nuclear marker 4',6-diamidino-2-phenylindole (Sigma) and finally mounted in Fluoromount (Sigma).

Neuronal survival assessment. Neurons from the same transfection batches were processed for PrP immunostaining $72 \mathrm{~h}$ after transfection (day 3 ) and $72 \mathrm{~h}$ after treatment with vehicle or resveratrol (day 6). The number of PrP-expressing neurons for each condition was assessed by counting 10 different microscopic fields per well (three wells per condition) and expressed as a ratio of PrP-expressing neurons versus the total number of cells. This provided a relative PrP expression factor (PF). Neuronal survival of PrP-expressing neurons was then assessed by comparing the PrP expression factors at day 6 versus day 3 . Neuronal survival was expressed as the ratio (PF at day 6$) /(\mathrm{PF}$ at day 3 ). Results represent the means of three independent experiments.

\section{Statistical analysis}

Statistics of nematode data were performed using one-way ANOVA followed by a Fisher's post hoc PLSD test. Statistics of mouse neuron data were performed using the student paired $t$ test. All experiments were repeated at least three times. $p<0.05$ was considered significant.

\section{Results}

\section{PG13-PrP expression causes neuronal dysfunction in \\ C. elegans}

To test whether mutant PrP may be neurotoxic in C. elegans, we used the promoter of the mec-7 ( $\beta$-tubulin) gene (Finney and Ruvkun, 1990) to express PG13-PrP in touch receptor neurons (supplemental Fig. S1 A, available at www.jneurosci.org as supplemental material) in the form of extrachromosomal arrays. We generated four wild-type $\operatorname{PrP}(\mathrm{Wt}-\mathrm{PrP})$ and four PG13-PrP lines, all of them carrying transgenes at the expected size (supplemental Fig. S1 $B$, available at www.jneurosci.org as supplemental material) and expressing transgenes at similar levels as tested by quantitative RT-PCR (supplemental Fig. S1C, available at www. jneurosci.org as supplemental material). These animals were tested for response to light touch at the tail, a phenotype under the control of two neurons, namely the PVM-L and PVM-R cells. The expression of Wt-PrP did not modify touch response at the tail compared to wild-type animals N2 (Fig. 1A). Compared to Wt-PrP expression, PG13-PrP expression produced a progressive neuronal dysfunction phenotype as tested in L3 and L4 larvae and young adult animals (Fig. $1 \mathrm{~A}$ ). The distribution of individual responses to light touch at the tail of adult PG13-PrP animals was typical of defective mechanosensation (Fig. $1 B$ ). To test for the pattern of prion protein expression, we crossed two extrachromosomal lines of each genotype (Wt-PrP or PG13-PrP) to animals stably expressing (integrated array) GFP in touch receptor neurons. The analysis of double transgenic animals confirmed that prion proteins were expressed in PVM cells (Fig. 1C) and that they were addressed at the cell surface membrane (Fig. 1D), as expected. This analysis also revealed that PG13-PrP formed clusters in cell bodies and axons similarly to what has been described for mouse PG14-PrP in mouse brain neurons (Medrano et al., 2008), a phenotype not detected for Wt-PrP (Fig. 1D,E). The analysis of double transgenic animals at the old adult stage further indicated that mutant PrP expression does not cause cell death (Fig. $1 F-H$ ).

\section{Mutant PrP in nematode neurons is partially resistant to proteinase $\mathrm{K}$ and shows insoluble properties}

Previous studies have indicated that mutant PrP may acquire PK resistance, a property characteristic of the pathogenic isoform. To test whether PG13-PrP may be PK resistant in C. elegans neurons, we analyzed protein extracts from transgenic worms by Western blot. First, we observed that Wt-PrP and the PG13-PrP proteins had an expected apparent molecular weight of $28-34 \mathrm{kDa}$ and $34-40 \mathrm{kDa}$, respectively (Fig. $2 \mathrm{~A}$ ), consistent with the pattern of migration of the human prion protein (Aguzzi et al., 2008a). These experiments also confirmed that transgenic lines expressed similar amount of PrP, either wild-type or mutant. As expected, control animals (N2) were deprived of prion protein immunoreactivity (Fig. 2A). To determine whether PG13-PrP may be resistant to proteolysis in C. elegans neurons, we incubated transgenic 
A

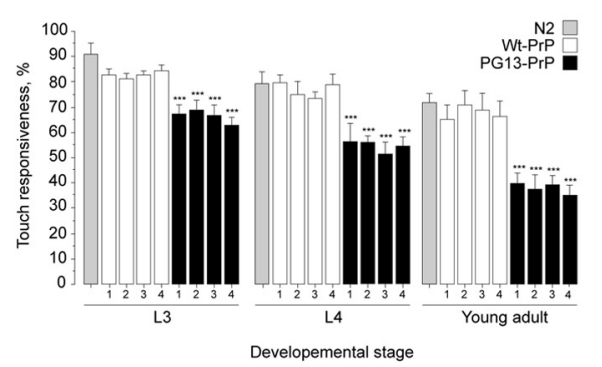

C

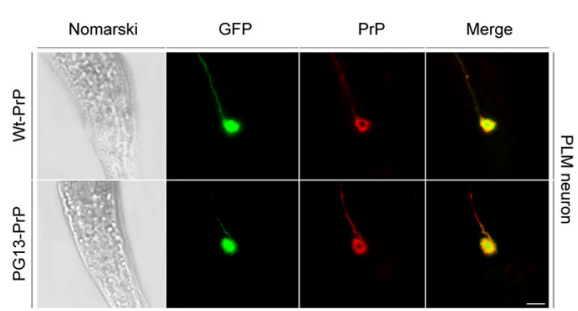

$E$

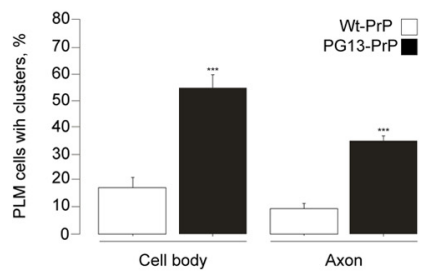

G

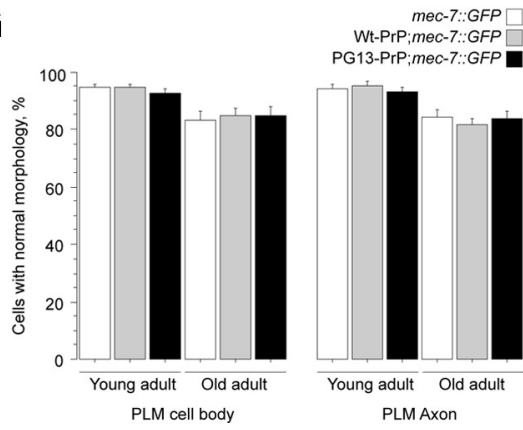

B

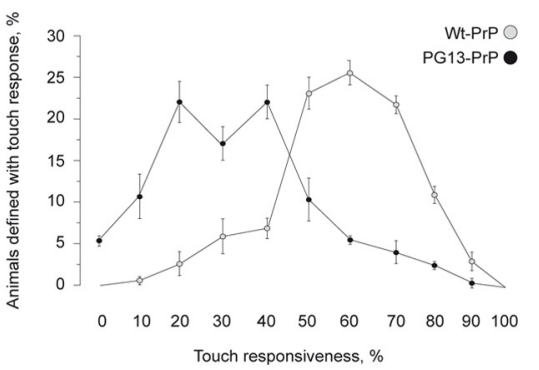

$\mathrm{D}$

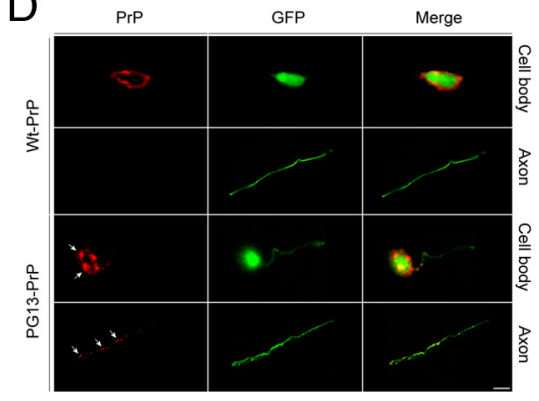

$\mathrm{F}$

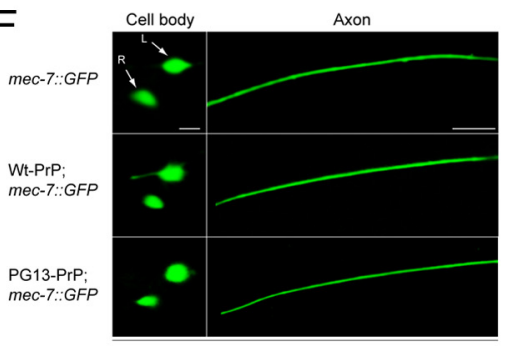

PLM neurons in old adults

$\mathrm{H}$

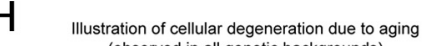
(observed in all genetic backgrounds)

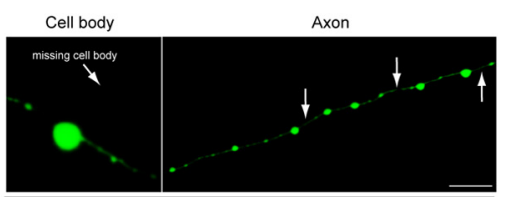

PLM neuron in old adults

Figure 1. Human mutant PrP produces a progressive neuronal dysfunction in C. elegans transgenics. A, Progressive loss of response to touch at the tail caused by mutant (PG13-PrP) PrP expression. Four lines of each genotype (Wt-PrP or PG13-PrP), all of them expressing similar levels of transgene (see supplemental Fig. 1, available at www.jneurosci.org as supplemental material, and Fig. $4 \mathrm{~A}$ ), were tested at different developmental stages (L3 larvae, L4 larvae, and young adults). Each bar corresponds to the mean \pm SEM for touch response at the tail. ${ }^{* * *} p<0.0001$ versus control (mean value for the four Wt-PrP lines). $\boldsymbol{B}$, Compared to a population of Wt-PrP animals, PG13-PrP animals show a shift toward insensitivity in the distribution of responsiveness/animal. The responses to light touch at the tail were recorded for every animal and expressed as mean percentage of responsiveness/ animal \pm SEM as shown on the $x$-axis. $C$, PrP is expressed in $P_{\text {mec- }-7}$ target cells. Two lines expressing either Wt-PrP or PG13-PrP were crossed with animals stably expressing GFP under the control of $P_{\text {mec-7. }}$. Shown here is a representative immunohistochemical analysis of PrP localization in PLM cells from young adults, with Nomarski analysis shown in the left panel. Magnification is $\times 63$ and scale bar is $5 \mu \mathrm{m}$. Posterior is to the bottom in all panels. $\boldsymbol{D}, \operatorname{PrP}$ is expressed at the cell body membrane, with accumulation detected in the cell body and axons for PG13-PrP. PrP expression was assessed using confocal analysis of PLM neurons in animals coexpressing GFP and PrP (2 lines/genotype) upon PrP immunostaining. Shown here are representative images of the most frequent phenotypes observed in PLM cells. Wt-PrP primarily shows diffuse expression at the cell body membrane, with few signals detected in the axon in some occasions. PG13-PrP expression shows clustering in the cell body and along the axonal process (white arrows). Magnification is $\times 100$ and scale bar is $2 \mu \mathrm{m}$. $\boldsymbol{E}$, Quantification of PrP clusters in PLM cells. Neurons expressing PG13-PrP exhibit a higher level of PrP clustering (mean \pm SEM) in the cell body and axon. ${ }^{* * *} p<0.001$ compared to Wt-PrP. $\boldsymbol{F}$, Representative confocal images of the most frequent morphology of PLM neurons in day-4 adults coexpressing GFP and PrP. R and L refer to the right and left PLM cells. Magnification is $\times 63$ and scale bar is $5 \mu \mathrm{m}$. Posterior is to the left in all panels. G, Quantification of PLM neurons showing a normal morphology in young (day 1 ) and old (day 4) adults. Two lines/genotype were scored, and $80-90 \%$ of

nematode homogenates with a range of PK concentrations. A weaker resistance was observed for PG13-PrP compared to human sporadic CJD brain samples (see PK at $10 \mu \mathrm{g} / \mathrm{ml}$ ), whereas nematode homogenates containing Wt-PrP and human control brain samples were fully digested at these concentrations (Fig. $2 B, C)$. The sensitivity to $\mathrm{PK}$ was different between the Wt-PrP lines and PG13-PrP lines (Fig. 2D), and the pattern of digestion for PG13-PrP showed a $19 \mathrm{kDa}$ PKresistant band similarly to that classically observed in human CJD brain extract (Cali et al., 2006). However the $19 \mathrm{kDa}$ band was difficult to detect in C. elegans samples under the protocol used herein. To reach a better comparison of the nematode and human samples, we purified PK-resistant PrP by using the scrapieassociated fibril protocol including a centrifugation step on a $20 \%$ sucrose cushion (Levavasseur et al., 2008; Brandel et al., 2009). Additionally, we used brain samples from a patient with GerstmannSträussler-Scheinker syndrome and the PG13 mutation as a control. Samples from this patient and from PG13-PrPexpressing animals showed a comparable pattern of PK-resistant PrP, with additional bands at $17-18 \mathrm{kDa}$ and $7-8 \mathrm{kDa}$ compared to PK-resistant PrP from sporadic CJD (Fig. 2E). Finally, we tested for PG13-PrP solubility into detergents. To this end, we separated nematode homogenates into soluble and sedimented protein fractions after incubation with detergents and centrifugation. Consistent with previous studies (Yuan et al., 2006), $\sim 70 \%$ of PG13-PrP was detected in the sedimented fraction, whereas $\sim 96 \%$ of Wt-PrP was detected in the soluble fraction (Fig. 2F), indicating that PG13-PrP has insoluble properties.

\section{Quinacrine reduces PG13-PrP}

neurotoxicity and proteinase-resistant PrP levels in nematodes

To test whether the phenotypes produced by PG13-PrP in nematodes may be manipulated by pharmacological means, we used the tricyclic derivative of acridine quinacrine, a know inhibitor of $\mathrm{PrP}^{\mathrm{Sc}}$ production (Korth et al., 2001). Micro-

normal PLM cells were detected in mutant PrP and control animals at the old adult stage. $\boldsymbol{H}$, Image of PLM cell degeneration in old adults. A weak level of cell body loss or axonal degeneration (white arrows) was observed in all the genetic background tested, thus corresponding to normal cellular senescence. Magnification is $\times 63$ and scale bar is $5 \mu \mathrm{m}$. Posterior is to the left in all panels. 
molar concentrations of quinacrine reversed the abnormal behavior of PG13PrP animals, with no effect detected in Wt-PrP animals (Fig. 3A; for raw touch responsiveness data, see supplemental Fig. S2, available at www.jneurosci.org as supplemental material). This therapeutic activity was unrelated to a change in transgene expression and prion protein expression (Fig. $3 B, C$, top). Consistent with its mode of action as an inhibitor of PrP conversion (Korth et al., 2001), quinacrine reduced the level of PK-resistant forms of PG13-PrP (Fig. 3C, bottom).

\section{Mutant PrP is neurotoxic via the \\ FYN-related kinase $s r c-2$}

Having shown that PG13-PrP is able to produce a neurological phenotype in nematode neurons that involves the production of PK-resistant molecules, we sought to examine whether mutant PrP neurocytotoxicity may also involve signaling pathways associated with cellular PrP signaling. To this end, we tested for the role of Fyn kinase since this kinase and member of the large Src oncogene related family tyrosine kinases (SFK family) was previously reported to have a role in cellular PrP signaling (Mouillet-Richard et al., 2000). Kinases of the SFK family are associated with plasma membranes and they are involved in initiating a variety of cellular events such as cell growth and division, cell attachment and movement, cellular differentiation, cell survival, and apoptosis (Thomas and Brugge, 1997). The C. elegans genome contains two fynrelated kinases, namely $s c r-1$ and $s r c-2 /$ kin-22 (Hirose et al., 2003), and we elected to use src-2 since it is the most characterized gene (Hirose et al., 2003). To test for the role of $s r c-2$ in PG13-PrP neurotoxicity, $\operatorname{PrP}$ nematodes were crossed with the loss-of-function (LOF) mutant scr-2(ok819) (Hirose et al., 2003) and assessed for response to light touch. The LOF mutation $s r c-2$ (ok819) strongly reduced the neuronal dysfunction induced by PG13-PrP expression, whereas it had no effect in $\mathrm{Wt}$ PrP animals (Fig. 4A; for raw touch responsiveness data, see supplemental Fig. $\mathrm{S} 3 A$, available at www.jneurosci.org as supplemental material). This effect was unrelated to a change in PG13-PrP expression (supplemental Fig. $\mathrm{S} 4 A$, available at www.jneurosci.org as supplemental material). Importantly, this effect was also unrelated to a change in PK-resistant PrP levels (supplemental Fig. S4 B, available at www.jneurosci.org as supplemental material). These results indicated that PG13-PrP is neurotoxic in C. elegans via the src-2/ FYN-related kinase and that $s r c-2$ modifies mutant $\operatorname{PrP}$ neurotoxicity regardless of the conversion of mutant PrP into a PK-resistant prion molecule.
A

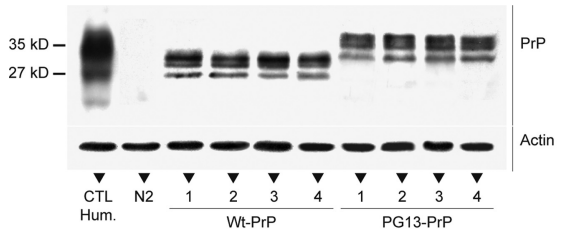

C
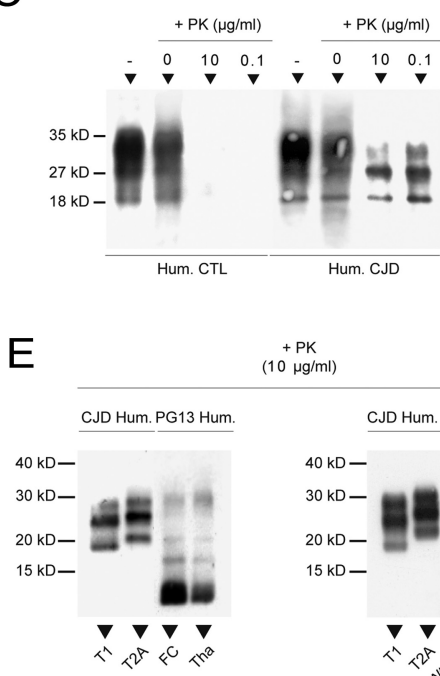

B

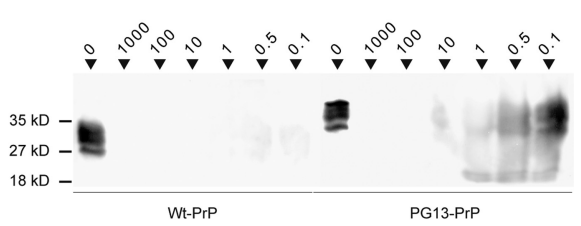

Wt-Pr

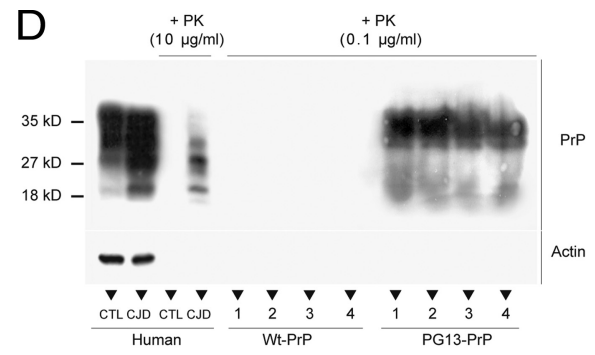

$\mathrm{F}$
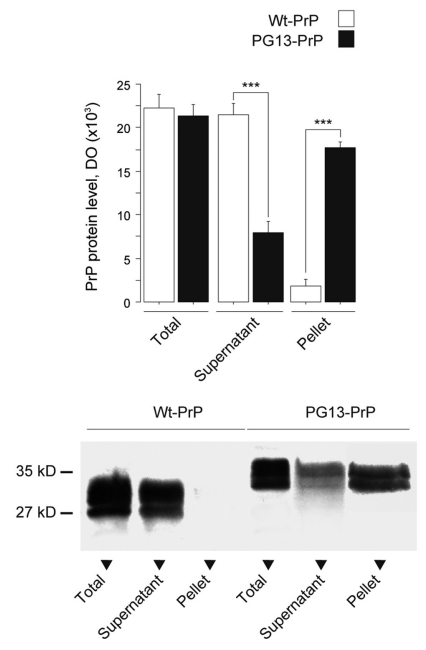

Figure 2. Biochemical properties of human prion protein expressed in C. elegans neurons. $\boldsymbol{A}$, Similar expression levels for transgenic PrP proteins as shown by Western blotting in the four lines expressing Wt-PrP and four lines expressing PG13-PrP. A molecular weight shift observed for PG13-PrP as expected. Human brain homogenate and protein extracts from the N2 nematode strain were used as controls. $\boldsymbol{B}$, Calibration of resistance to PK digestion using PK at 1000 to 0.1 $\mu \mathrm{g} / \mathrm{ml}$. PG13-PrP is partially resistant to PK digestion in a PK-concentration-dependent manner, whereas Wt-PrP is not resistant to $P K$ at all the enzyme concentrations tested. $C$, The resistance of PG13-PrP to PK digestion is weaker than that of sporadic CJD PrP ${ }^{S C}$. PG13-PrP is resistant to PK in a dose-dependent manner ( $10 \mu \mathrm{g} / \mathrm{ml}$ and $\left.0.1 \mu \mathrm{g} / \mathrm{ml}\right)$ at concentrations that fully degrade PrP from healthy human brain (human CTL). At these concentrations, PrP from human brain CJD (Hum (JD) is PK resistant, indicating that PG13-PrP show partial and weaker PK resistance compared to PrP from human CJD. $D$, Resistance to PK digestion in lines expressing PG13-PrP. Prion protein in the PG13-PrP lines are partially protected from PK digestion, whereas Wt-PrP lines do not show PK resistance. Healthy (CTL) and sporadic disease (CJD) human brain homogenates were used as digestion controls. $\boldsymbol{E}$, Western blot signature of PK-resistant PrP associated with the PG13 mutation. T1, Control sample with PK-resistant PrP type 1 from patient with sporadic CJD. T2A, Control sample with PK-resistant PrP type 2A from a patient with sporadic CJD. FC, Frontal cortex from a patient with the PG13 mutation. Tha, Thalamus from a patient with the PG13 mutation. WT, C. elegans line expressing wild-type PrP. PG13, C. elegans line expressing PG13-PrP. Samples from a patient with the PG13 mutation and from PG13-PrP-expressing animals showed a comparable pattern of PK-resistant PrP ${ }^{\text {res }}$ with, compared to PrP res type from sporadic CJD, additional bands at 17-18 and 7-8 kDa. F, PG13-PrP is insoluble. Upon fractionation, Wt-PrP is primarily found in the soluble fraction, whereas mutant PrP is primarily found in the sedimented fraction.

\section{Sir-2.1/SIRT1 rescues neuronal dysfunction in mutant PrP} nematodes without reducing proteinase-resistant PrP levels Next, we examined whether the sirtuin and key longevity modulator sir-2.1/SIRT1 (Tissenbaum and Guarente, 2001), a nicotinamide adenine dinucleotide (NAD)-dependent histone deacetylase, may be able to protect nematode neurons from mutant PrP. We elected to study the effects of sir-2.1/SIRT1 on mutant PrP neurotoxicity because sirtuin manipulation has therapeutic potential in several models of degenerative diseases, 


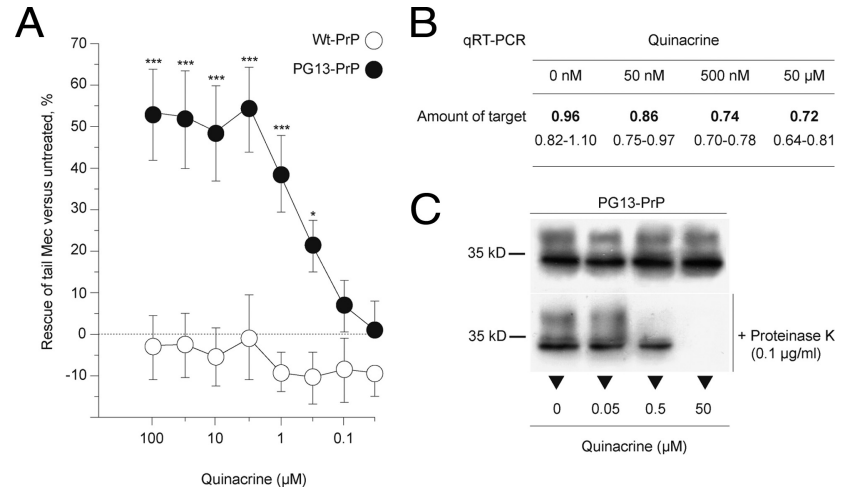

Figure 3. Quinacrine protects $C$. elegans neurons from the effects of PG13-PrP expression. $A$, Quinacrine reversed neuronal dysfunction (mean \pm SEM) in PG13-PrP animals with no effect detected in Wt-PrP animals. Three independent lines were tested per genotype. ${ }^{*} p<0.05$ and ${ }^{* * *} p<0.0001$ versus untreated PG13-PrP animals. B, Quinacrine does not alter PG13-PrP transgene expression as detected by RT-PCR. C, Representative Western blot showing that quinacrine does not alter the expression level of the mutated prion protein and restores sensitivity to PK digestion.

including Huntington's disease (Parker et al., 2005), microgliadependent amyloid $\beta$ toxicity (Chen et al., 2005), inherited Parkinson's disease (Outeiro et al., 2007), and oculopharyngeal muscular dystrophy (OPMD) (Catoire et al., 2008). The LOF mutant sir-2.1(ok434) enhanced neuronal dysfunction induced by PG13-PrP expression with no effect detected in animals expressing Wt-PrP (Fig. 4A; for raw touch responsiveness data, see supplemental Fig. S3A, available at www.jneurosci.org as supplemental material). This effect was unrelated to a change in PG13PrP expression (supplemental Fig. S4C, available at www. jneurosci.org as supplemental material) and to a change in proteinase-resistant PrP levels (supplemental Fig. S4D, available at www.jneurosci.org as supplemental material). Consistently, increased sir-2.1 dosage (sir2.1(O/E)) reversed the neuronal dysfunction induced by PG13-PrP expression with no effect detected in animals expressing Wt-PrP (Fig. $4 A$; for raw touch responsiveness data, see supplemental Fig. S2 A, available at www.jneurosci. org as supplemental material). This effect was unrelated to a change in PG13-PrP expression (supplemental Fig. S4 E, available at www.jneurosci.org as supplemental material) and to a change in PK-resistant PrP levels (supplemental Fig. S4F, available at www.jneurosci.org as supplemental material). Thus, SIR-2.1 activation protects neurons from mutant PrP neurotoxicity, and this effect is not due to inhibition of mutant PrP conversion into a PK-resistant PrP molecule.

\section{Resveratrol rescues mutant PrP neurotoxicity in nematode and mouse neurons}

Having shown that Sir2 protects from PG13-PrP neurotoxicity in C. elegans, we sought to examine whether a similar effect may be achieved by pharmacological means. To this end, we used resveratrol, a polyphenolic compound known to act via Sir2 for protection of diseased neurons in several models of neurodegenerative diseases (Chen et al., 2005; Parker et al., 2005; Kim et al., 2007). Resveratrol reversed neuronal dysfunction in PG13-PrP animals with no effect detected in Wt-PrP animals (Fig. $4 B$; for raw touch responsiveness data, see supplemental Fig. S3B, available at www.jneurosci.org as supplemental material). This effect was not due to a change in PrP transgene expression (supplemental Fig. S4E, available at www.jneurosci.org as supplemental material). Additionally, the neuroprotective effect of this compound

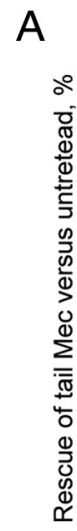

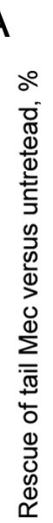

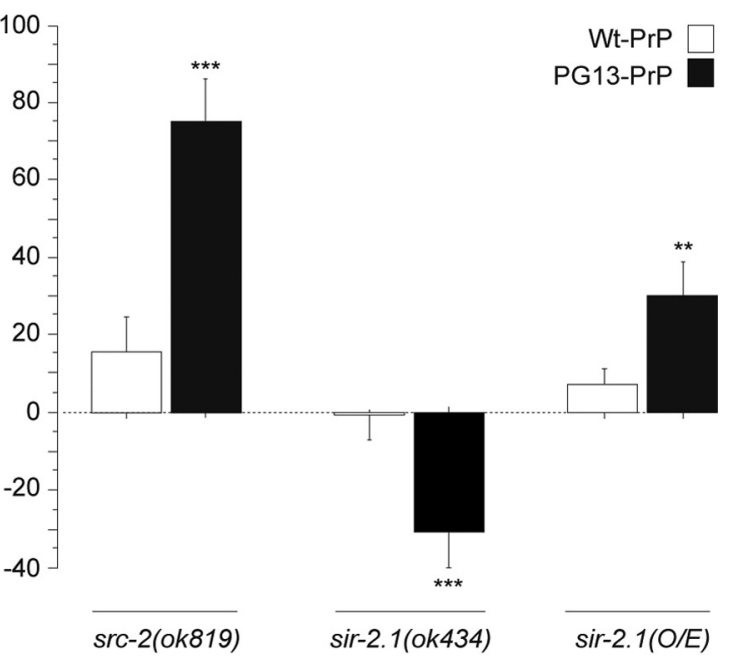

B

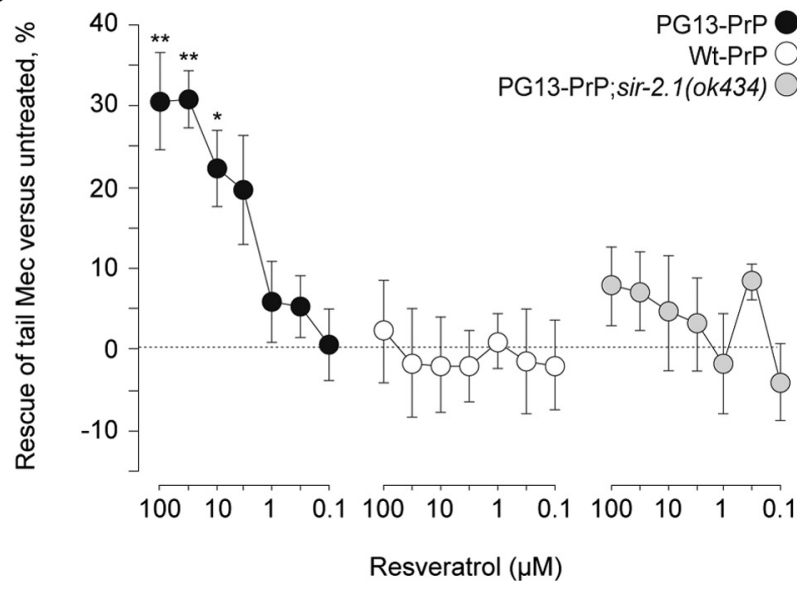

Figure 4. Modulation of PG13-PrP cytotoxicity in C. elegans neurons by scr-2/FRK, sir-2.1/ SIRT1, and resveratrol. $A$, The LOF src-2 (ok819) greatly reduced neuronal dysfunction in PG13PrP animals with no effect seen in Wt-PrP animals. This effect was not due to a change in the resistance to PK digestion (see supplemental Fig. S4A, available at www.jneurosci.org as supplemental material), nor to a change in PG-13-PrP expression levels (supplemental Fig. S4B, available at www.jneurosci.org as supplemental material). Increased sir-2.1 dosage specifically rescues neuronal dysfunction in PG13-PrP animals, whereas a sir-2.1 deletion allele (ok434) enhanced neuronal dysfunction. These effects were not due to a change in the resistance to PK digestion (see supplemental Fig. S4C,E, available at www.jneurosci.org as supplemental material), nor to a change in PG-13-PrP expression levels (supplemental Fig. S4D,F, available at www.jneurosci.org as supplemental material). Results are given as the percentage of rescue (mean $\pm \mathrm{SEM}$ ), a negative value means aggravation, and the maximal achievable rescue is $100 \%$ (see Materials and Methods). Three independent lines were tested per genotype. ${ }^{* * *} p<$ $0.0001 ;{ }^{* *} p<0.001$ compared to PrP transgenics. $\boldsymbol{B}$, Resveratrol rescues neuronal dysfunction in PG13-PrP animals with no effect seen in Wt-PrP animals. This effect was not due to a change in PG13-PrP expression levels (supplemental Fig. S2G, available at www.jneurosci.org as supplemental material). Rescue by resveratrol is lost in PG13-PrP transgenics harboring sir-2.1 LOF. Three independent lines were tested per genotype. ${ }^{* *} p<0.001$; ${ }^{*} p<0.05$ compared to animals treated with vehicle.

was lost in the sir-2.1 LOF (ok434) background (Fig. $4 \mathrm{~B}$; for raw touch responsiveness data, see supplemental Fig. S3B, available at www.jneurosci.org as supplemental material), indicating that the rescue of mutant PG13-PrP toxicity by resveratrol is mediated by Sir 2 .

We also tested whether resveratrol may protect mouse neurons against mutant PrP. To this end, primary cultures of cerebellar granule neurons from mice null for $\operatorname{PrP}\left(\operatorname{Prnp}^{-1-}\right)$ were transfected with mouse Wt-PrP and PG14-PrP. Costaining of 
A
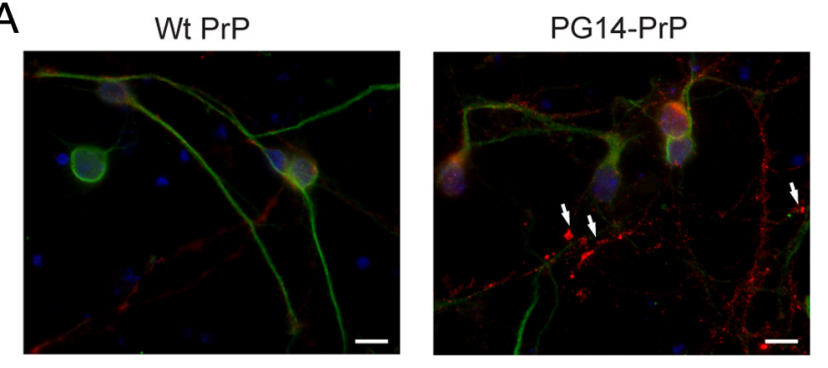

B

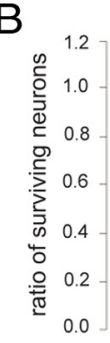

C
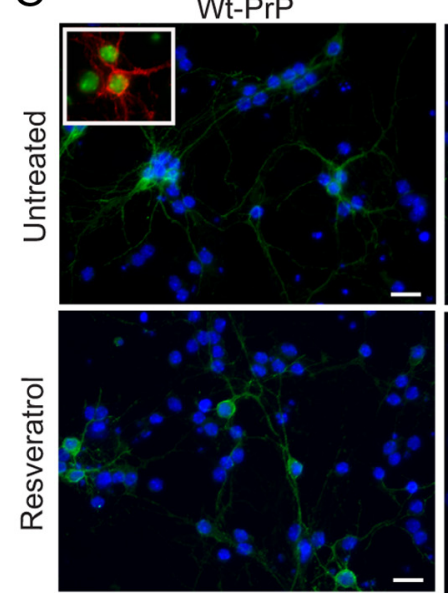

$* * *$

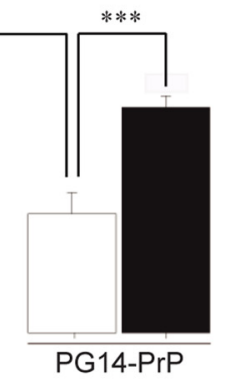

Untreated

Resveratrol
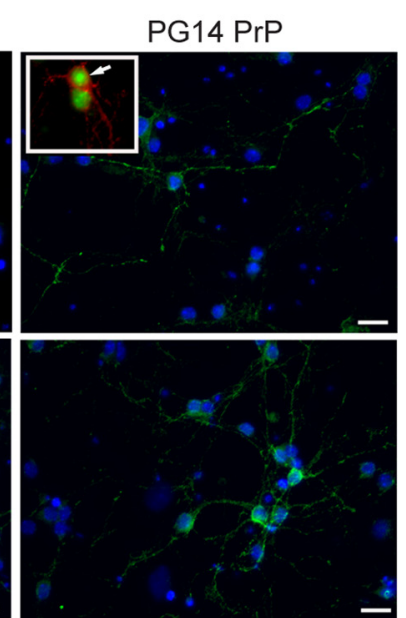

Figure 5. Resveratrol protects mouse neurons from cell death induced by human mutant (PG14-PrP) prion protein expression. $\boldsymbol{A}$, Representative images of cerebellar granule neurons transfected with Wt-PrP or PG14-PrP constructs. To detect intracellular aggregated form of PG14, cells were permeabilized and immunostained after $4 \mathrm{~d}$ of culture (green, dendritic MAP2; red, PrP; blue, DAPI). Wt-PrP and PG14-PrP are expressed in cell bodies and neuronal processes (note that intracellular Wt-PrP staining is fainter than membrane-bound PrP signal in C). Accumulation and aggregation in neuronal processes (white arrows) is observed for PG14-PrP. Magnification is $\times 400$ and scale bar is $10 \mu \mathrm{m}$. B , Quantification of PG14-PrP-induced neuronal death and neuroprotection by resveratrol. Data are expressed as the mean ratio \pm SEM of surviving cells at day 6 compared to day 3 after transfection. A ratio equal to 1 means no cell death.PG14-PrP expression strongly alters neuronal survival ( $\left.{ }^{* * *} p<0.0001\right)$, whereas Wt-PrP expression has no effect. Resveratrol (duration of treatment: $72 \mathrm{~h}$ starting at day 3 after transfection) prevents neuronal death induced by PG14-PrP expression. ${ }^{* *} p<0.0001$. C, Representative fields of cerebellar granule neurons transfected with Wt-PrP or PG14-PrP and treated for $72 \mathrm{~h}$ with either vehicle or resveratrol. Membrane-bound (no permeabilization) forms of PrP are immunostained after $6 \mathrm{~d}$ in culture (green, membrane-bound PrP; blue, cell nuclei, DAPI). Note the drastic reduction in PrP-expressing cell number caused by PG14-PrP expression in untreated neurons. Magnification is $\times 200$ and scale bar is $20 \mu \mathrm{m}$. Inset [red, membrane-bound PrP; yellow, nuclear DAPI (pseudocolor)] shows a healthy Wt-PrP-expressing neuron, whereas remaining PG14expressing neurons shows condensed chromatin (white arrow) with dystrophic neurites.

mouse neurons with MAP2 antibodies (staining of dendrites only in cerebellar granule neurons) and $\operatorname{PrP}$ antibodies indicated that PrP was primarily expressed at the periphery of cell bodies and along neuritic processes, with a significant level of intracellular protein accumulation and presence of dystrophic dendrites observed for mutant $\operatorname{PrP}$ (Fig. 5A), which is consistent with previous observations on PG14-PrP pattern of expression (Medrano et al., 2008). Mutant PrP caused death of mouse neurons at day 6 after transfection, while Wt-PrP showed no effect, and resveratrol strongly reversed the toxic effect of PG14-PrP with no effect detected in Wt-PrP neurons (Fig. 5B). Rescue by resveratrol was unrelated to a change in mutant PrP expression levels as inferred from analysis of dendrites (Fig. $5 C$ ). It is interesting to note that resveratrol treatment did not modify the clustered pattern of PG14-PrP expression along neuritic processes (Fig. 5C). Thus, resveratrol protects PrP-null mouse neurons from cell death induced by mutant PrP.

\section{Discussion}

Our data indicate that human mutant PrP expression is able to alter neuronal cell activity in C. elegans transgenics, providing a unique system to uncover the modifiers of the early phases (cell dysfunction without cell death) of protein toxicity in vivo. The $C$. elegans amenability to genetic and pharmacological analyses may indeed uncover aspects of PrP cytotoxicity difficult to manipulate in vivo by other means. Furthermore, the availability of a highly penetrant neurotoxic phenotype in C. elegans provides a model suitable in suppressor screens. Interestingly, these animals recapitulate an important component of mutant $\mathrm{PrP}$ toxicity, namely, the production and toxicity of PK-resistant and insoluble PrP (Telling et al., 1996; Chiesa et al., 1998). Additionally, these animals reveal that the alteration of proteins known to be involved in cellular PrP signaling such as Fyn-related kinases is involved in mutant PrP neurotoxicity (Mouillet-Richard et al., 2007). Human PrP is usually $N$-glycosylated in two sites and produces a typical triple-band pattern in Western blot experiments (Lawson et al., 2005). In nematodes, Wt-PrP and PG13PrP also showed the triple-band pattern reminiscent of the protein glycosylation of PrP.

Although PK resistance of mutant PrP in nematodes was weaker than that of $\operatorname{PrP}^{\mathrm{Sc}}$ from human CJD brains, mutant $\operatorname{PrP}$ produced a strong neurological phenotype in nematodes. This is consistent with the notion that PK resistance and toxicity may be not strictly correlated as observed in Tg mice (Fischer et al., 1996; Manson et al., 1999). The production of PK-resistant PrP and the alteration of intracellular signaling are two pathological components likely to underlie neurotoxicity in mutant PrP nematodes. Regarding the first component, the rescue of neuronal dysfunction by quinacrine, an inhibitor of pathogenic PrP forms in vitro and in cell cultures (Korth et al., 2001), indicates that the selfconversion of mutant PrP into PK-resistant prion molecules can be pharmacologically manipulated in these nematodes. This provides a basis and method to search for new inhibitors of pathogenic forms of PrP in vivo. This may enhance antiprion drug discovery since the ability of putative antiprion drugs such as quinacrine to protect from pathogenic $\mathrm{PrP}$ in mice may be questionable (Collins et al., 2002; Gayrard et al., 2005). Regarding the second component, the strong reduction of neuronal dysfunction in the $s r c-2$ LOF background with no effect on PK-resistant PrP levels indicates that mutant PrP may directly alter intracellular signaling. This observation reveals that a particular Fyn homolog in C. elegans is involved in PG-13 PrP neurotoxicity, suggesting that Fyn kinases may be involved in prion neurotoxicity in addition to their role in cellular PrP signaling (MouilletRichard et al., 2007). Future studies will determine whether FYN kinases may play a role in mutant PrP neurotoxicity and whether the effectors involved in cellular PrP signaling downstream to FYN such as ERK1/2 (Schneider et al., 2003) may also participate to mutant PrP signaling. 
Together with the fact that human prionopathies do not affect a specific neuronal cell type or brain area (DeArmond and Prusiner, 1995; DeArmond and Bouzamondo, 2002), the biochemical and biological features of mutant PrP expression in the touch receptor neurons of $C$. elegans transgenics identify these animals as a relevant model to study the pathogenesis and modification of inherited CJD. Other simple models of prionopathies have been described. A truncated and cytosolic mouse prion protein $(\mathrm{MoPrP}(23-231))$ fused to CFP was previously expressed in nematode muscle cells and reported to alter several processes including development and mobility (Park and Li, 2008). This study concluded that the prion folding mechanism may be similar in nematodes and mammals, which is also supported by our comparison of the $\mathrm{PK}$ resistance of pathogenic PrP in nematode neurons and human CJD brain. However, the type of cell targets (muscle cells) and PrP species (cytoplasmic protein) used in this study (Park and Li, 2008) may limit the relevance of this model to study the neurotoxic effects of the full-length prion protein. An octarepeat-expanded form of PrP was previously expressed in the Drosophila eye, however with no phenotype produced, a situation likely to result from the existence of a mechanism that suppresses the production of misfolded $\operatorname{PrP}$ (Deleault et al., 2003). Here, our data support the notion that octarepeat expansion may confer to $\operatorname{PrP}$ the ability to misfold into pathogenic conformers and produce neurotoxicity as previously documented by the expression of mouse PG14-PrP in BHK cells (Ivanova et al., 2001) and transgenic mice (Chiesa et al., 1998). Our data are also consistent with the ability of mutant PrP expression to produce a neurological phenotype in invertebrates as previously reported for the P101L mouse PrP in Drosophila (Gavin et al., 2006). Among the mechanisms that may contribute to mutant $\operatorname{PrP}$ neurotoxicity is the delayed exit from the endoplasmic reticulum as documented for PG14-PrP in BHK cells (Ivanova et al., 2001). Although we cannot exclude this possibility, our genetic data in nematodes (modulation by src-2/FRK and sir-2.1/SIRT1) suggest that mutant PrP neurotoxicity may primarily arise from the cell surface, affecting downstream signaling.

Sirtuins are key longevity/cell survival modulators, and their manipulation is neuroprotective in several models of degenerative disease pathogenesis including Wallerian degeneration (Araki et al., 2004), HD (Parker et al., 2005), microglia-mediated amyloid- $\beta$ toxicity (Chen et al., 2005), Alzheimer's disease/ tauopathies and amyotrophic lateral sclerosis (Kim et al., 2007), $\alpha$-synuclein toxicity (Outeiro et al., 2007), and OPMD (Catoire et al., 2008). It is intriguing that in models of expanded polyglutamine toxicity (HD), increased sir-2.1/SIRT1 dosage protects diseased cells (Parker et al., 2005), whereas in models of expanded polyalanine toxicity (OPMD), it is detrimental to cell survival, with sir-2.1/SIRT1 inhibition being beneficial (Catoire et al., 2008). It is also intriguing that both SIRT1 activation (Chen et al., 2005; Parker et al., 2005) and SIRT2 inhibition (Outeiro et al., 2007) may be neuroprotective. Whether sirtuins may be activated or inhibited to achieve neuroprotection is still debated (Dillin and Kelly, 2007). Since sirtuins belong to a network of genes that is finely tuned in response to stress (Brunet et al., 2004), the net outcome of manipulating sirtuins in diseased cell protection may be greatly influenced by (1) the sirtuin being manipulated (SIRT1, SIRT2, and SIRT3 have different subcellular localizations and activities), (2) the level of acetylation of the sirtuin targets that are affected by the pathology (Catoire et al., 2008), and (3) the strength of cellular stress (cell death vs cell dysfunction) induced in the model system (Parker et al., 2005; Pallos et al., 2008). Regarding sirtuins and prions, it was recently reported by Chen et al. (2008) that the onset of disease induced by infection of mice with the RML prion strain is delayed in SIRT1 KO mice. This appears to contrast with protection of nematode neurons by increased sir-2.1/SIRT1 dosage. However, infectivity and neurotoxicity may be distinct properties of PrP (Solomon et al., 2009) and the two studies address different prion pathologies. The study by Chen et al. (2008) primarily addressed infectivity, showing that SIRT1 may influence PrP expression and that delayed onset of prion disease (severe neuronal loss and gliosis) in SIRT1 KO mice may involve a reduction of PrP expression, which is a well known determinant of prion infectivity. This protective mechanism is not addressed in PG13-PrP nematodes since $C$. elegans does not have a prion protein. Nonetheless, the data from Chen et al. (2008) together with those reported herein suggest that sirtuins may protect against certain pathological components of prion diseases while exacerbating others, highlighting the complexity of manipulating prion diseases.

Resveratrol is neuroprotective against expanded huntingtin (Parker et al., 2005) and microglia-dependent amyloid- $\beta$ toxicity (Chen et al., 2005) and active in models of Alzheimer's disease/ tauopathies and amyotrophic lateral sclerosis (Kim et al., 2007). While resveratrol may be an indirect sirtuin activator and may activate other cellular targets such as AMP kinase (Dasgupta and Milbrandt, 2007), many of resveratrol's effects are consistent with activation of SIRT1 and modulation of its targets (Baur, 2009). In support of this notion, neuroprotection from expanded polyglutamines by resveratrol was lost in nematodes with sir-2.1 LOF and in huntingtin knock-in mouse striatal cells treated with the sirtuin inhibitor sirtinol (Parker et al., 2005). Consistently, the rescue of mutant PrP neurotoxicity by resveratrol was lost in sir-2.1 mutants. The protection from mutant PrP by resveratrol in nematode neurons and prnp-null mouse neurons thus calls for sirtuin activators to be evaluated in animal models of inherited prion diseases. Future studies will address the activity of SIRT1selective activators (Milne et al., 2007; Feige et al., 2008) in this respect.

In conclusion, we generated C. elegans transgenics that allow the neurotoxicity of mutant $\operatorname{PrP}$ to be manipulated in vivo. $\mathrm{Mu}-$ tant PrP forms clusters in neurons, is partially resistant to proteinase $\mathrm{K}$, shows insoluble properties, and induces neuronal dysfunction. The src-2/Fyn-related kinase mediates a neurotoxic component that is unrelated to the conversion of mutant PrP into a proteinase-resistant prion. Increased sir-2.1/SIRT1 dosage protects from this neurotoxic phenotype without affecting proteinase-resistant $\mathrm{PrP}$, and the indirect sirtuin activator resveratrol protects nematode and mouse neurons from mutant PrP toxicity. Collectively, these data suggest that SIRT1 activators have therapeutic potential in prion diseases to protect neurons from the detrimental effects of misfolded PrP conformers on intracellular signaling and homeostasis.

\section{References}

Aguzzi A, Sigurdson C, Heikenwaelder M (2008a) Molecular mechanisms of prion pathogenesis. Annu Rev Pathol 3:11-40.

Aguzzi A, Baumann F, Bremer J (2008b) The prion's elusive reason for being. Annu Rev Neurosci 31:439-477.

Araki T, Sasaki Y, Milbrandt J (2004) Increased nuclear NAD biosynthesis and SIRT1 activation prevent axonal degeneration. Science 305:10101013.

Baur JA (2009) Biochemical effects of SIRT1 activators. Biochim Biophys Acta. Advance online publication. Retrieved Jan. 22, 2010. doi:10.1016/j.bbapap.2009.10.025.

Bolton DC, McKinley MP, Prusiner SB (1984) Molecular characteristics of the major scrapie prion protein. Biochemistry 23:5898-5906.

Brandel JP, Heath CA, Head MW, Levavasseur E, Knight R, Laplanche JL, 
Langeveld JP, Ironside JW, Hauw JJ, Mackenzie J, Alpérovitch A, Will RG, Haïk S (2009) Variant Creutzfeldt-Jakob disease in France and the United Kingdom: evidence for the same agent strain. Ann Neurol 65: 249-256.

Brenner S (1974) The genetics of Caenorhabditis elegans. Genetics 77:71-94. Brunet A, Sweeney LB, Sturgill JF, Chua KF, Greer PL, Lin Y, Tran H, Ross SE, Mostoslavsky R, Cohen HY, Hu LS, Cheng HL, Jedrychowski MP, Gygi SP, Sinclair DA, Alt FW, Greenberg ME (2004) Stress-dependent regulation of FOXO transcription factors by the SIRT1 deacetylase. Science 303:2011-2015.

Büeler H, Fischer M, Lang Y, Bluethmann H, Lipp HP, DeArmond SJ, Prusiner SB, Aguet M, Weissmann C (1992) Normal development and behaviour of mice lacking the neuronal cell-surface PrP protein. Nature 356:577-582.

Cali I, Castellani R, Yuan J, Al-Shekhlee A, Cohen ML, Xiao X, Moleres FJ, Parchi P, Zou WQ, Gambetti P (2006) Classification of sporadic Creutzfeldt-Jakob disease revisited. Brain 129:2266-2277.

Catoire H, Pasco MY, Abu-Baker A, Holbert S, Tourette C, Brais B, Rouleau GA, Parker JA, Néri C (2008) Sirtuin inhibition protects from the polyalanine muscular dystrophy protein PABPN1. Hum Mol Genet 17:21082117.

Chen D, Steele AD, Hutter G, Bruno J, Govindarajan A, Easlon E, Lin SJ, Aguzzi A, Lindquist S, Guarente L (2008) The role of calorie restriction and SIRT1 in prion-mediated neurodegeneration. Exp Gerontol 43:10861093.

Chen J, Zhou Y, Mueller-Steiner S, Chen LF, Kwon H, Yi S, Mucke L, Gan L (2005) SIRT1 protects against microglia-dependent beta amyloid toxicity through inhibiting NF-kappa B signaling. J Biol Chem 280:4036440374.

Chiesa R, Piccardo P, Ghetti B, Harris DA (1998) Neurological illness in transgenic mice expressing a prion protein with an insertional mutation. Neuron 21:1339-1351.

Collins SJ, Lewis V, Brazier M, Hill AF, Fletcher A, Masters CL (2002) Quinacrine does not prolong survival in a murine Creutzfeldt-Jakob disease model. Ann Neurol 52:503-506.

Cronier S, Beringue V, Bellon A, Peyrin JM, Laude H (2007) Prion strainand species-dependent effects of antiprion molecules in primary neuronal cultures. J virology 81:13794-13800.

Dasgupta B, Milbrandt J (2007) Resveratrol stimulates AMP kinase activity in neurons. Proc Natl Acad Sci U S A 104:7217-7222.

DeArmond SJ, Bouzamondo E (2002) Fundamentals of prion biology and diseases. Toxicology 181-182:9-16.

DeArmond SJ, Prusiner SB (1995) Etiology and pathogenesis of prion diseases. Am J Pathol 146:785-811.

Deleault NR, Dolph PJ, Feany MB, Cook ME, Nishina K, Harris DA, Supattapone S (2003) Post-transcriptional suppression of pathogenic prion protein expression in Drosophila neurons. J Neurochem 85:1614-1623.

Dillin A, Kelly JW (2007) Medicine. The yin-yang of sirtuins. Science 317: 461-462.

Feige JN, Lagouge M, Canto C, Strehle A, Houten SM, Milne JC, Lambert PD, Mataki C, Elliott PJ, Auwerx J (2008) Specific SIRT1 activation mimics low energy levels and protects against diet-induced metabolic disorders by enhancing fat oxidation. Cell Metab 8:347-358.

Finney M, Ruvkun G (1990) The unc-86 gene product couples cell lineage and cell identity in C. elegans. Cell 63:895-905.

Fischer M, Rülicke T, Raeber A, Sailer A, Moser M, Oesch B, Brandner S, Aguzzi A, Weissmann C (1996) Prion protein (PrP) with aminoproximal deletions restoring susceptibility of PrP knockout mice to scrapie. EMBO J 15:1255-1264.

Gavin BA, Dolph MJ, Deleault NR, Geoghegan JC, Khurana V, Feany MB, Dolph PJ, Supattapone S (2006) Accelerated accumulation of misfolded prion protein and spongiform degeneration in a Drosophila model of Gerstmann-Straussler-Scheinker syndrome. J Neurosci 26:12408-12414.

Gayrard V, Picard-Hagen N, Viguié C, Laroute V, Andréoletti O, Toutain PL (2005) A possible pharmacological explanation for quinacrine failure to treat prion diseases: pharmacokinetic investigations in a ovine model of scrapie. Br J Pharmacol 144:386-393.

Hirose T, Koga M, Ohshima Y, Okada M (2003) Distinct roles of the Src family kinases, SRC-1 and KIN-22, that are negatively regulated by CSK-1 in C. elegans. FEBS Lett 534:133-138.

Ivanova L, Barmada S, Kummer T, Harris DA (2001) Mutant prion proteins are partially retained in the endoplasmic reticulum. J Biol Chem 276:42409-42421.

Iwasaki M, Okumura K, Kondo Y, Tanaka T, Igarashi H (1992) cDNA cloning of a novel heterogeneous nuclear ribonucleoprotein gene homologue in Caenorhabditis elegans using hamster prion protein cDNA as a hybridization probe. Nucleic Acids Res 20:4001-4007.

Kim D, Nguyen MD, Dobbin MM, Fischer A, Sananbenesi F, Rodgers JT, Delalle I, Baur JA, Sui G, Armour SM, Puigserver P, Sinclair DA, Tsai LH (2007) SIRT1 deacetylase protects against neurodegeneration in models for Alzheimer's disease and amyotrophic lateral sclerosis. EMBO J 26:3169-3179.

Korth C, May BC, Cohen FE, Prusiner SB (2001) Acridine and phenothiazine derivatives as pharmacotherapeutics for prion disease. Proc Natl Acad Sci U S A 98:9836-9841.

Laplanche JL, Hachimi KH, Durieux I, Thuillet P, Defebvre L, DelasnerieLauprêtre N, Peoc'h K, Foncin JF, Destée A (1999) Prominent psychiatric features and early onset in an inherited prion disease with a new insertional mutation in the prion protein gene. Brain 122:2375-2386.

Lawson VA, Collins SJ, Masters CL, Hill AF (2005) Prion protein glycosylation. J Neurochem 93:793-801.

Lehmann S, Harris DA (1995) A mutant prion protein displays an aberrant membrane association when expressed in cultured cells. J Biol Chem 270:24589-24597.

Lehmann S, Harris DA (1996) Two mutant prion proteins expressed in cultured cells acquire biochemical properties reminiscent of the scrapie isoform. Proc Natl Acad Sci U S A 93:5610-5614.

Leliveld SR, Dame RT, Wuite GJ, Stitz L, Korth C (2006) The expanded octarepeat domain selectively binds prions and disrupts homomeric prion protein interactions. J Biol Chem 281:3268-3275.

Levavasseur E, Laffont-Proust I, Morain E, Faucheux BA, Privat N, Peoc'h K, Sazdovitch V, Brandel JP, Hauw JJ, Haïk S (2008) Regulating factors of PrP glycosylation in Creutzfeldt-Jakob disease-implications for the dissemination and the diagnosis of human prion strains. PLoS One 3:e2786.

Linden R, Martins VR, Prado MA, Cammarota M, Izquierdo I, Brentani RR (2008) Physiology of the prion protein. Physiol Rev 88:673-728.

Livak KJ, Schmittgen TD (2001) Analysis of relative gene expression data using real-time quantitative PCR and the $2(-$ Delta Delta $\mathrm{C}(\mathrm{T}))$ method. Methods 25:402-408.

Manson JC, Jamieson E, Baybutt H, Tuzi NL, Barron R, McConnell I, Somerville R, Ironside J, Will R, Sy MS, Melton DW, Hope J, Bostock C (1999) A single amino acid alteration (101L) introduced into murine PrP dramatically alters incubation time of transmissible spongiform encephalopathy. EMBO J 18:6855-6864.

McKinley MP, Bolton DC, Prusiner SB (1983) A protease-resistant protein is a structural component of the scrapie prion. Cell 35:57-62.

Medrano AZ, Barmada SJ, Biasini E, Harris DA (2008) GFP-tagged mutant prion protein forms intra-axonal aggregates in transgenic mice. Neurobiol Dis 31:20-32.

Mello C, Fire A (1995) DNA transformation. Methods Cell Biol 48: 451-482.

Milne JC, Lambert PD, Schenk S, Carney DP, Smith JJ, Gagne DJ, Jin L, Boss O, Perni RB, Vu CB, Bemis JE, Xie R, Disch JS, Ng PY, Nunes JJ, Lynch AV, Yang H, Galonek H, Israelian K, Choy W, et al. (2007) Small molecule activators of SIRT1 as therapeutics for the treatment of type 2 diabetes. Nature 450:712-716.

Mouillet-Richard S, Ermonval M, Chebassier C, Laplanche JL, Lehmann S, Launay JM, Kellermann O (2000) Signal transduction through prion protein. Science 289:1925-1928.

Mouillet-Richard S, Schneider B, Pradines E, Pietri M, Ermonval M, Grassi J, Richards JG, Mutel V, Launay JM, Kellermann O (2007) Cellular prion protein signaling in serotonergic neuronal cells. Ann N Y Acad Sci 1096:106-119.

Outeiro TF, Kontopoulos E, Altmann SM, Kufareva I, Strathearn KE, Amore AM, Volk CB, Maxwell MM, Rochet JC, McLean PJ, Young AB, Abagyan R, Feany MB, Hyman BT, Kazantsev AG (2007) Sirtuin 2 inhibitors rescue alpha-synuclein-mediated toxicity in models of Parkinson's disease. Science 317:516-519.

Pallos J, Bodai L, Lukacsovich T, Purcell JM, Steffan JS, Thompson LM, Marsh JL (2008) Inhibition of specific HDACs and sirtuins suppresses pathogenesis in a Drosophila model of Huntington's disease. Hum Mol Genet 17:3767-3775. 
Park KW, Li L (2008) Cytoplasmic expression of mouse prion protein causes severe toxicity in Caenorhabditis elegans. Biochem Biophys Res Commun 372:697-702.

Parker JA, Connolly JB, Wellington C, Hayden M, Dausset J, Neri C (2001) Expanded polyglutamines in Caenorhabditis elegans cause axonal abnormalities and severe dysfunction of PLM mechanosensory neurons without cell death. Proc Natl Acad Sci U S A 98:13318-13323.

Parker JA, Arango M, Abderrahmane S, Lambert E, Tourette C, Catoire H, Néri C (2005) Resveratrol rescues mutant polyglutamine cytotoxicity in nematode and mammalian neurons. Nat Genet 37:349-350.

Prusiner SB, Hsiao KK (1994) Human prion diseases. Ann Neurol 35: 385-395.

Schneider B, Mutel V, Pietri M, Ermonval M, Mouillet-Richard S, Kellermann O (2003) NADPH oxidase and extracellular regulated kinases $1 / 2$ are targets of prion protein signaling in neuronal and nonneuronal cells. Proc Natl Acad Sci U S A 100:13326-13331.
Solomon IH, Schepker JA, Harris DA (2009) Prion neurotoxicity: insights from prion protein mutants. Curr Issues Mol Biol 12:51-62.

Telling GC, Haga T, Torchia M, Tremblay P, DeArmond SJ, Prusiner SB (1996) Interactions between wild-type and mutant prion proteins modulate neurodegeneration in transgenic mice. Genes Dev 10:1736-1750.

Thomas SM, Brugge JS (1997) Cellular functions regulated by Src family kinases. Annu Rev Cell Dev Biol 13:513-609.

Tissenbaum HA, Guarente L (2001) Increased dosage of a sir-2 gene extends lifespan in Caenorhabditis elegans. Nature 410:227-230.

Westergard L, Christensen HM, Harris DA (2007) The cellular prion protein $(\operatorname{PrP}(\mathrm{C}))$ : its physiological function and role in disease. Biochim Biophys Acta 1772:629-644.

Yuan J, Xiao X, McGeehan J, Dong Z, Cali I, Fujioka H, Kong Q, Kneale G, Gambetti P, Zou WQ (2006) Insoluble aggregates and proteaseresistant conformers of prion protein in uninfected human brains. J Biol Chem 281:34848-34858. 